\title{
Detection of antibiotic resistance in probiotics of dietary supplements
}

\author{
Aloysius Wong ${ }^{1}$, Davey Yueh Saint Ngu², Lydia Annabel Dan², Amanda Ooi ${ }^{1}$ and Renee Lay Hong Lim²*
}

\begin{abstract}
Background: Probiotics are live microorganisms that confer nutrition- and health-promoting benefits if consumed in adequate amounts. Concomitant with the demand for natural approaches to maintaining health is an increase in inclusion of probiotics in food and health products. Since probiotic bacteria act as reservoir for antibiotic resistant determinants, the transfer of these genes to pathogens sharing the same intestinal habitat is thus conceivable considering the fact that dietary supplements contain high amounts of often heterogeneous populations of probiotics. Such events can confer pathogens protection against commonly-used drugs. Despite numerous reports of antibiotic resistant probiotics in food and biological sources, the antibiogram of probiotics from dietary supplements remained elusive.
\end{abstract}

Findings: Here, we screened five commercially available dietary supplements for resistance towards antibiotics of different classes. Probiotics of all batches of products were resistant towards vancomycin while batch-dependent resistance towards streptomycin, aztreonam, gentamycin and/or ciprofloxacin antibiotics was detected for probiotics of brands $\mathrm{Bi}$ and $\mathrm{Bn}, \mathrm{Bg}$, and $\mathrm{L}$. Isolates of brand $\mathrm{Cn}$ was also resistant towards gentamycin, streptomycin and ciprofloxacin antibiotics. Additionally, we also report a discrepancy between the enumerated viable bacteria amounts and the claims of the manufacturers.

Conclusions: This short report has highlighted the present of antibiotic resistance in probiotic bacteria from dietary supplements and therefore serves as a platform for further screenings and for in-depth characterization of the resistant determinants and the molecular machinery that confers the resistance.

\section{Findings Introduction}

Probiotics are live microorganisms usually bacteria or yeasts, that confer health-promoting benefits to the host if consumed in adequate amounts. These benefits range from improvement of intestinal health [1] and immune response [2], to prevention of acute and antibiotic-associated diarrhea [1], and cancer [3]. The health-promoting attributes, mechanisms and strainspecific benefits have been extensively reviewed elsewhere [4]. Probiotic foods have gained widespread acceptance and popularity $[5,6]$ as reflected by an estimated growth of more than $10 \%$ in economic value from 2009 to 2014 [7]. Due to increasing consumer demand for natural non-drug approaches to improve health,

\footnotetext{
*Correspondence: reneelim@ucsiuniversity.edu.my

${ }^{2}$ UCSI University, No. 1, Jalan Menara Gading, UCSI Heights, Cheras, 56000

Kuala Lumpur, Malaysia

Full list of author information is available at the end of the article
}

probiotic bacteria have been included in overwhelming number of food products especially in dairy foods such as the probiotic-containing yoghurt, cheese, milk and ice-cream [8].

Widespread use of probiotic bacteria in conjunction and in close association with antibiotic use or rather misuse, can over time establish a reservoir of antibiotic resistant genes in probiotic bacteria [9]. While intrinsic antibiotic resistance can be a desirable trait as probiotics help restore host gut microflora during a course of antibiotics, however the transfer of resistant genes to pathogenic bacteria offers serious clinical threats [10]. There is already a wide collection of literature reporting resistance of lactic acid bacteria towards antibiotics of the beta-lactams, macrolide, aminoglycoside, chloramphenicol and tetracycline classes $[6,11]$ and in some, their corresponding resistant genes and mechanisms have been characterized $[9,12]$. Importantly, resistant gene transfer that occurs at high frequency and persist 
across generations have also been demonstrated in vitro and/or in vivo among Lactobacilli and from Lactobacilli to pathogens [13] and vice versa [14]. These reports have established probiotic bacteria as reservoir of antibiotic resistant genes that can be transferred to pathogenic strains.

While the detection of antibiotic resistance in probiotic strains from food and biological sources have intensified, such reports from dietary supplements have remained somewhat elusive. This is surprising considering the fact that probiotic dietary supplements contain high amount and often a heterogeneous population of probiotic bacteria both of which, are conditions that encourage the trafficking of resistant genes. Therefore, we hypothesize that antibiotic resistant probiotics may be present in dietary supplements.

\section{Methods}

Probiotic dietary supplements designated here as $\mathrm{Bi}$, $\mathrm{Bn}, \mathrm{Bg}, \mathrm{Cn}$ and $\mathrm{L}$, were purchased from local pharmacy or retail outlets (Table 1) and the ampicillin, aztreonam, erythromycin, gentamycin, streptomycin, clindamycin, vancomycin, ciprofloxacin, cephalexin and tetracycline antibiotic discs were purchased from HiMedia, India

Table 1 The information of probiotic bacteria in dietary supplements

\begin{tabular}{|c|c|c|c|}
\hline Product & Country manufactured & Probiotic content & $\begin{array}{l}\text { Probiotic amount } \\
\left(\times 10^{6} \mathrm{CFU} / \text { capsule }\right)\end{array}$ \\
\hline \multirow[t]{4}{*}{$\mathrm{Bi}$} & \multirow[t]{4}{*}{ Malaysia } & $\begin{array}{l}\text { B. longum, } \\
\text { B. bifidum, }\end{array}$ & \multirow[t]{4}{*}{$5,000^{*}$} \\
\hline & & $\begin{array}{l}\text { B. infantis, } \\
\text { L. bulgaricus, }\end{array}$ & \\
\hline & & $\begin{array}{l}\text { L. rhamnosus, } \\
\text { L. casei, }\end{array}$ & \\
\hline & & L. acidophilus & \\
\hline \multirow[t]{2}{*}{$\mathrm{Bn}$} & \multirow[t]{2}{*}{ Austria } & $\begin{array}{l}\text { B. longum, } \\
\text { B. bifidum, }\end{array}$ & \multirow[t]{2}{*}{10} \\
\hline & & L. gasseri & \\
\hline \multirow[t]{3}{*}{$\mathrm{Bg}$} & \multirow[t]{3}{*}{ Malaysia } & L. acidophilus, & \multirow[t]{3}{*}{$2,000^{*}$} \\
\hline & & L. rhamnosus, & \\
\hline & & B. longum & \\
\hline \multirow[t]{3}{*}{$\mathrm{Cn}$} & \multirow[t]{3}{*}{ U.S.A } & L. acidophilus, & \multirow[t]{3}{*}{8} \\
\hline & & $\begin{array}{l}\text { L. salivarius, } \\
\text { B. bifidum, }\end{array}$ & \\
\hline & & S. thermophiles, & \\
\hline \multirow[t]{4}{*}{$\mathrm{L}$} & \multirow[t]{4}{*}{ Malaysia } & L. acidophilus, & \multirow[t]{4}{*}{$10,000^{*}$} \\
\hline & & $\begin{array}{l}\text { L. bulgaricus, } \\
\text { L. casei, }\end{array}$ & \\
\hline & & B. longum, & \\
\hline & & S. thermophilus & \\
\hline
\end{tabular}

*One capsule contains equal amounts of each probiotic strain. In products where such information is not stated, equal contributions from each probiotic content is assumed
(Table 2). In order to recover and enumerate probiotic bacteria [15], one capsule of dietary supplement was dissolved in sterile double distilled water [16] and immediately platted on the de Man, Rogosa and Sharpe (MRS) media (Difco, USA) which is selective for Lactobacilli. We note that Lactobacilli constitute the majority of the probiotic bacteria population in the dietary supplements (Table 1) and have therefore excluded contributions of other probiotic strains from the bacteria count and from the subsequent antibiotic resistance screening (Additional file 1). One capsule contains equal amounts of each probiotic strain. In products where such information is not stated, equal contributions from each probiotic content is assumed. The dissolved samples $\left(10^{6} \mathrm{CFU}\right)$ were cultured overnight in MRS broth for enrichment of probiotic bacteria after which the overnight culture was adjusted to uniform concentrations of $7 \times 10^{6} \mathrm{CFU} / \mathrm{mL}$ of bacteria by spectroscopy $\left(\mathrm{OD}_{690 \mathrm{~nm}}\right)$ prior to antibiotic susceptibility tests using commercial antibiotic discs and according to the manufacturer's instructions (Additional file 1).

\section{Results and discussion}

Viable bacteria were recovered on MRS media and their amounts were enumerated prior to antibiotic susceptibility tests. Probiotic bacteria, particularly the Lactobacilli strains, from all brands of dietary supplements were successfully recovered on MRS agar (Fig. 1a). The recovered bacteria have different colony morphologies of which two are particularly distinctive. One, a larger sized opaque colony is present in all brands at similar amounts to the other colony type that is smaller in size and translucent, but appears to be far fewer in brands $\mathrm{Bn}$ and $\mathrm{L}$ respectively (Fig. 1a). This suggests that there is more than one type of probiotic strain in the respective products and this is consistent with the claims of the manufacturers (Table 1). The bacteria enumeration revealed that with the exception of brand $\mathrm{Bn}$, samples from all brands have bacteria amounts that are fewer than that claimed by their manufacturers (Fig. 1b). Most significant of these are samples from brands $\mathrm{Bi}$, $\mathrm{Bg}$ and $\mathrm{L}$ which have viable bacteria of only $6 \%, 22 \%$ and $3 \%$ of the amounts stated on their respective datasheets. The bacteria concentration of brand $\mathrm{Cn}$ is $57 \%$ of that claimed by the manufacturer while brand $\mathrm{Bn}$ has a surprising bacteria count that is more than double the stated amount. The enumerated bacteria amounts were however above the recommended minimum threshold of $10^{6} \mathrm{CFU} /$ capsule [17]. The overestimation of probiotic amounts in four of the five products tested suggest that 1) a significant amounts of bacteria have been compromised during the processing stages which may include improper handling and storage conditions or 2) the manufacturers have 
Table 2 Classification and mode of action of antibiotics

\begin{tabular}{lll}
\hline Antibiotic & Class & Spectrum \\
\hline Ampicillin $(10 \mathrm{mcg})$ & Semi-synthetic beta lactams & Gram positive and Gram negative \\
Aztreonam $(30 \mathrm{mcg})$ & Mono-bactams & Gram positive and Gram negative \\
Erythromycin $(15 \mathrm{mcg})$ & Macrolides & Gram positive and Gram negative \\
Gentamicin $(5 \mathrm{mcg})$ & Aminoglycosides & Gram positive and Gram negative, especially Pseudomonas \\
Streptomycin $(10 \mathrm{mcg})$ & Gram positive and Gram negative \\
Clindamycin $(2 \mathrm{mcg})$ & Lincomycins & Gram positive and Gram negative, especially anaerobic Bacteroides \\
Vancomycin $(30 \mathrm{mcg})$ & Glycopeptides & Gram positive and Gram negative, especially S. aureus \\
Cephalexin $(30 \mathrm{mcg})$ & Cephalosporin & Gram positive \\
Tetracycline $(30 \mathrm{mcg})$ & Tetracycline & Gram positive and Gram negative \\
Ciprofloxacin $(10 \mathrm{mcg})$ & Fluoroquinolones & Gram positive and Gram negative, especially Bacillus anthracis \\
\hline
\end{tabular}
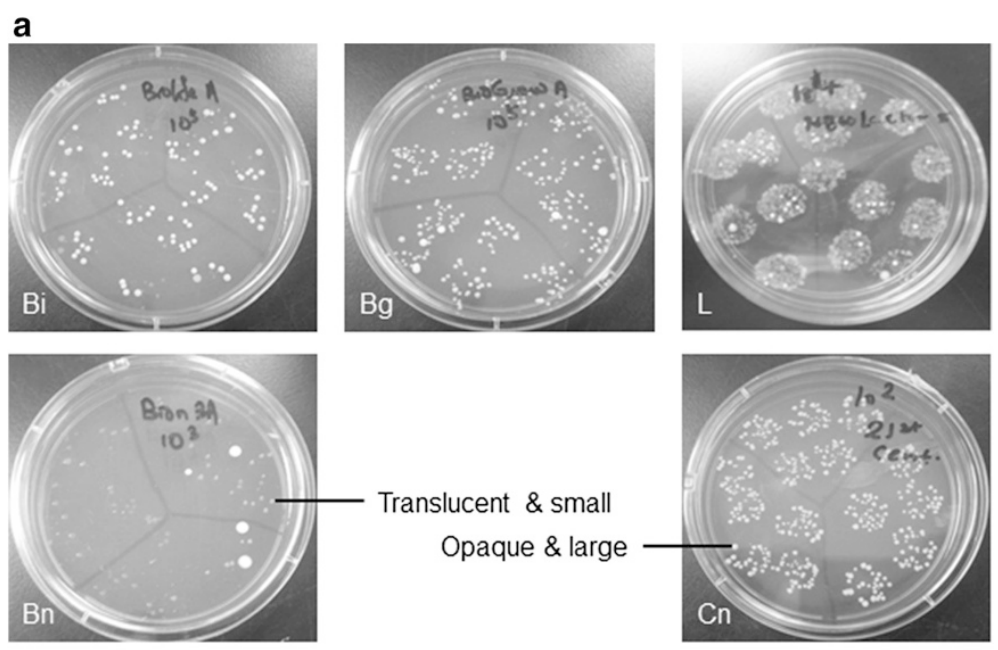

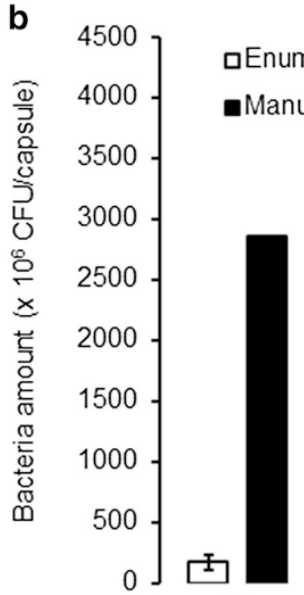

$\mathrm{Bi}$

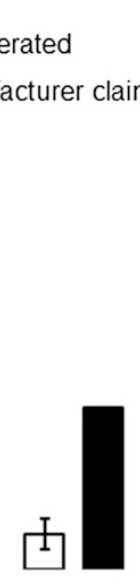

$\mathrm{Bg}$

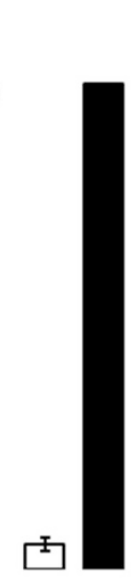

$\mathrm{L}$

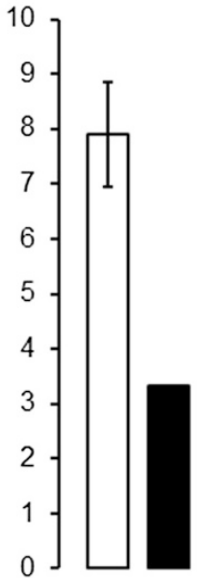

$\mathrm{Bn}$

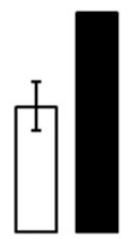

$\mathrm{Cn}$

Fig. 1 The recovery and enumeration of probiotic bacteria from dietary supplements. (a) Representative MRS agar plates of probiotics bacteria recovered from $\mathrm{Bi}, \mathrm{Bg}, \mathrm{L}, \mathrm{Bn}$ and $\mathrm{Cn}$ dietary supplements showing different colony morphologies and densities. (b) Comparison of the enumerated probiotics bacteria to that claimed by the manufacturers of the respective products (Table 1). Error bars represent standard error of the mean $(n=2)$ 
deliberately overestimated the probiotic content of the products in an attempt to compete for consumers [18]. This finding seems to agree with other reports concerning mislabeling, overestimation and misidentification of probiotics in various food and health products [19]. It is therefore doubtful that the health claims of the respective products can be achieved by the inferior amounts of viable probiotic bacteria although some reports have claimed that viability is not essential and that probiotic DNA or cell wall materials may be sufficient to confer certain health effects [20]. This enumeration provides useful preliminary data shedding light on the accuracy and reliability of the probiotic bacteria information detailed on the datasheet of dietary supplements as regulations and legislations concerning product labeling are currently lacking [21].

In the antibiotic resistant screening, clear inhibition zones of $>0.5 \mathrm{~cm}$ were measured from the bacteria lawn of isolates from all batches of brands $\mathrm{Bi}, \mathrm{Bn}, \mathrm{Bg}, \mathrm{Cn}$ and L towards ampicillin, erythromycin, clindamycin, cephalexin and tetracycline antibiotics (Fig. 2b), suggesting no resistance towards these antibiotics. Meanwhile, inhibition zones detected in only certain batches of the probiotic products were that of brands $\mathrm{Bi}$ and $\mathrm{Bn}, \mathrm{Bg}$ and $\mathrm{L}$ in the presence of the respective streptomycin, aztreonam and gentamycin, streptomycin and ciprofloxacin antibiotics (Fig. 2b). This batch-to-batch variation implies that these resistances were not conferred by intrinsic genes but more likely a result of acquired mobile genetic elements by a transfer event and this is a concern because mobile elements such as plasmids and transposons can be transferred from one cell to another by conjugation [10]. Indeed, this mechanism has been demonstrated in vitro where antibiotic resistant gene transferred from one Lactobacillus to another and more worryingly, also from Lactobacilli to other species including pathogenic strains such as Staphylococcus [13] and vice versa [22]. Streptomycin and gentamycin belong to the aminoglycosides and resistance towards this group of antibiotic may be conferred by intrinsic Lactobacilli aminoglycoside resistant genes aac(6')-aph(2"), ant(6), and aph(3')-IIIa respectively [11]. Consistent
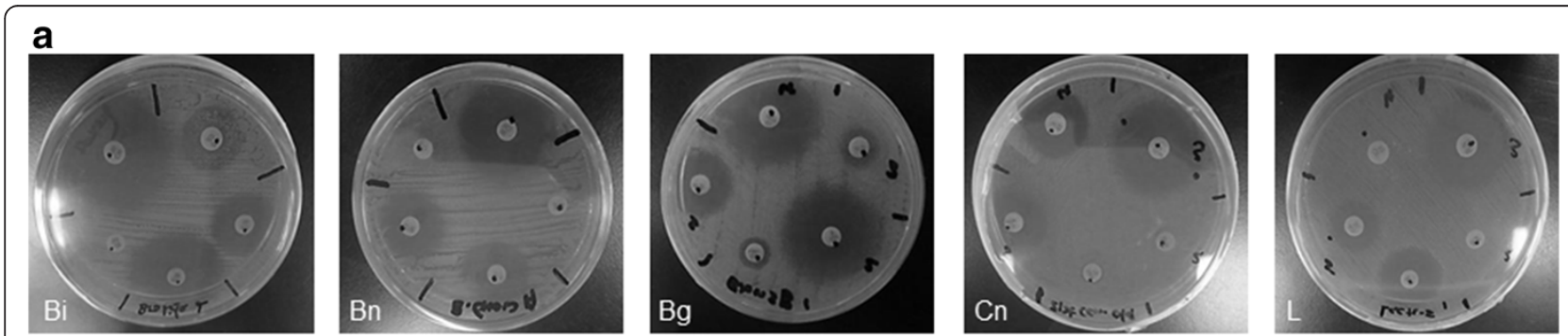

b

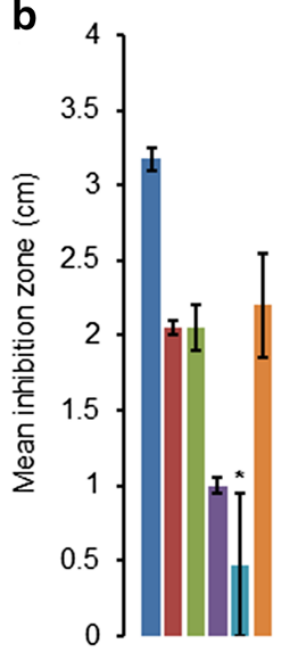

$\mathrm{Bi}$

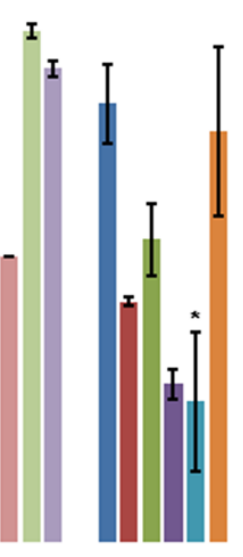

$\mathrm{Bn}$

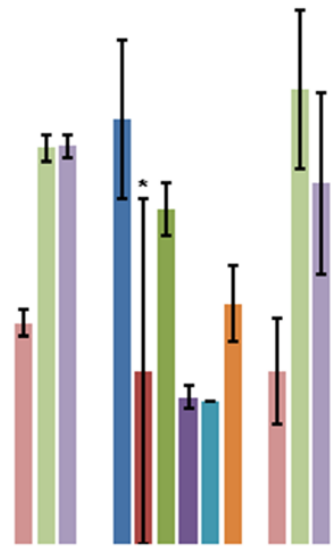

$\mathrm{Bg}$

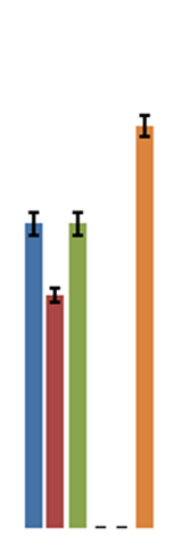

$\mathrm{Cn}$

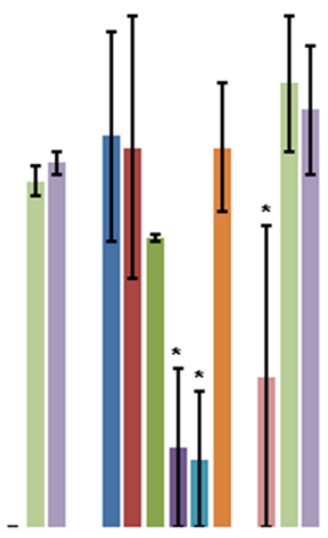

$\mathrm{L}$
Ampicillin - Aztreonam Erythromycin - Gentamycin ॥ Streptomycin - Clindamycin - Vancomycin — Ciprofloxacin - Cephalexin n Tetracycline

Fig. 2 The antibiotic susceptibility profile of probiotic bacteria in the dietary supplements. (a) Representative MRS agar plates of bacteria lawn of $\mathrm{Bi}, \mathrm{Bn}, \mathrm{Bg}, \mathrm{Cn}$ and $\mathrm{L}$ dietary supplements layered with antibiotic discs showing susceptibility towards multiple antibiotics as characterized by the presence of 'clear' inhibition zones. (b) Mean inhibition zones measured from the bacteria lawn of Bi, Bn, Bg, Cn and L dietary supplements layered with the respective antibiotic discs. Error bars represent standard error of the mean $(n \geq 2)$ and $\left(^{*}\right)$ represents inhibition zone present in only certain batches of bacteria in the respective dietary supplement 
with this speculation, bacteria of brand $\mathrm{Cn}$ also showed no inhibition zone against the gentamycin and streptomycin antibiotics besides also being resistant towards ciprofloxacin (Fig. 2b). While resistance towards aztreonam, a derivative of the beta-Iactam antibiotics, may be conferred by the blaZ genes which have also been previously found in Lactobacilli [2], detection of ciprofloxacin resistance could not be attributed to known fluoroquinolone resistance genes as they have not been identified in Lactobacilli. Although probiotic bacteria (predominantly Lactobacilli) of all products were able to grow in the presence of vancomycin (Fig. 2b), this is attributed to intrinsic vancomycin resistant genes in Lactobacilli strains rather than a transfer event. This intrinsic resistant gene prevents vancomycin binding at the cytoplasmic end of their cell walls due to replacement of the terminal amino acid residue [23]. Notably, tetracycline and erythromycin resistance were not detected in isolates of all brands although genes conferring resistance towards these classes of antibiotics (i.e. the tetracycline and macrolides) are well-characterized in Lactobacilli [24]. Although reports on antibiotic resistance in probiotic isolates of dietary supplements are elusive, such data from foods [12] and biological sources [25] are widely reported $[6,9,16]$. Further, resistant determinants have also been identified with the resistance genes of tetracycline $(>10)$, aminoglycoside (at least 4 ) and beta-lactam [12] constituting an expanding list of genetic elements in Lactobacilli.

In summary, this is a pilot study that reports the present of antibiotic resistance in probiotic bacteria in dietary supplements thus expanding the screening of antibiotic resistance to include this largely unexplored but increasingly popular group of functional foods. This study also serves as a platform for further screenings and in-depth characterization of the resistant determinants and the molecular machinery that confers the resistance. In particular, resistant probiotics can be isolated and identified by a combination of biochemical tests and 16S rRNA gene sequencing analysis and the antibiotic resistant genes characterized using degenerate primers and/or a motif-based identification approach [26]. Manufacturing companies of dietary supplements should incorporate antibiotic susceptibility screening using diagnostic tools such as microarray chips and PCR approaches in the production chain. Additionally, curative strategies such as the removal of genetic elements that harbor antibiotic resistance could also be applied to the relevant probiotic strains. The latter has been applied to the probiotic L. reuteri DSM 17938 whereby two resistant plasmids were successfully removed from the parent $L$. reuteri (ATCC 55730) [27] while not affecting the probiotic properties of the strain.

\section{Additional file}

Additional file 1: Extended Materials and Methods.

Competing interests

The authors declare that they have no competing interests.

\section{Authors' contribution}

$\mathrm{RL}$ conceived the project and supervised the work; DN and DLA performed the experiments; AW and AO performed the data analysis; and AW and RL wrote the manuscript. All authors read and approved the manuscript.

\section{Acknowledgements}

We thank the Faculty of Applied Sciences, UCSI University and King Abdullah University of Science and Technology for supporting this research.

\section{Author details}

${ }^{1}$ Division of Biological and Environmental Sciences and Engineering, 4700 King Abdullah University of Science and Technology, Thuwal 23955-6900, Saudi Arabia. ${ }^{2}$ UCSI University, No. 1, Jalan Menara Gading, UCSI Heights, Cheras, 56000 Kuala Lumpur, Malaysia.

Received: 2 May 2015 Accepted: 7 September 2015

Published online: 14 September 2015

\section{References}

1. Kaur IP, Chopra K, Saini A. Probiotics: potential pharmaceutical applications. Eur J Pharm Sci. 2002;15:1-9.

2. Perdigon G, Fuller R, Raya R. Lactic acid bacteria and their effect on the immune system. Curr Issues Intest Microbiol. 2001;2:27-42.

3. Hirayama K, Rafter J. The role of probiotic bacteria in cancer prevention. Microbes Infect. 2000;2:681-6.

4. Kechagia M, Basoulis D, Konstantopoulou S, Dimitriadi D, Gyftopoulou K, Skarmoutsou N, et al. Health benefits of probiotics: a review. ISRN Nutr. 2013;2013:481651.

5. Stanton C, Gardiner G, Meehan H, Collins K, Fitzgerald G, Lynch PB, et al. Market potential for probiotics. Am J Clin Nutr. 2001;73:476S-83S.

6. Sharma P, Tomar SK, Goswami P, Sangwan SR. Antibiotic resistance among commercially available probiotics. Food Res Int. 2014;57:176-95.

7. Markets and Markets: In: Probiotic market-advanced technologies and global market (2009-2014). 2009. http://www.marketsandmarkets.com/ Market-Reports/probiotic-market-advanced-technologies-and-global-market69.html. Accessed 28 January 2015.

8. Homayouni A, Alizadeh M, Alikhah H, Zijah V: Functional Dairy Probiotic Food Development: Trends, Concepts, and Products. In: Everlon Rigobelo, editor. Probiotics. InTech 2012. doi:10.5772/48797. 2012

9. Mathur S, Singh R. Antibiotic resistance in food lactic acid bacteria-a review. Int J Food Microbiol. 2005;105:281-95.

10. Broaders E, Gahan CG, Marchesi JR. Mobile genetic elements of the human gastrointestinal tract: potential for spread of antibiotic resistance genes. Gut Microbes. 2013:4:271-80.

11. Devirgiliis C, Zinno P, Perozzi G. Update on antibiotic resistance in foodborne Lactobacillus and Lactococcus species. Front Microbiol. 2013;4:301.

12. Gueimonde M, Sanchez B, G de Los Reyes-Gavilan C, Margolles A. Antibiotic resistance in probiotic bacteria. Front Microbiol. 2013;4:202.

13. Tannock GW, Luchansky JB, Miller L, Connell H, Thode-Andersen S, Mercer AA, et al. Molecular characterization of a plasmid-borne (pGT633) erythromycin resistance determinant (ermGT) from Lactobacillus reuteri 100-63. Plasmid. 1994;31:60-71.

14. Mater DDG, Langella P, Corthier G, Flores MJ. A Probiotic Lactobacillus strain can acquire vancomycin resistance during digestive transit in mice. J Mol Microbiol Biotechnol. 2008;14:123-7.

15. Munsch-Alatossava P, Alatossava T. Antibiotic resistance of raw-milkassociated psychrotrophic bacteria. Microbiol Res. 2007;162:115-23.

16. Sharma P, Tomar SK, Sangwan V, Goswami P, Singh R: Antibiotic resistance of Lactobacillus sp. isolated from commercial probiotic preparations. J Food Safety 2015, doi:10.1111/jfs.12211.

17. Shah NP. Probiotic bacteria: selective enumeration and survival in dairy foods. J Dairy Sc. 2000;83:894-907. 
18. Farnworth ER. The evidence to support health claims for probiotics. J Nutr. 2008;138:1250S-4S.

19. Hamilton-Miller JMT, Shah $\mathrm{S}$, Winkler JT. Public health issues arising from microbiological and labelling quality of foods and supplements containing probiotic microorganisms. Public Health Nutr. 1999;2:223-9.

20. Lahtinen SJ: Probiotic viability - does it matter? Microb Ecol Health D 2012, 23:doi:10.3402/mehd.v23i0.18567.

21. Przyrembel H. Consideration of possible legislation within existing regulatory frameworks. Am J Clin Nutr. 2001;73:471s-5s.

22. Vescovo M, Morelli L, Bottazzi V, Gasson MJ. Conjugal transfer of broadhost-range plasmid pAMbeta1 into Enteric species of lactic acid bacteria. Appl Environ Microbiol. 1983;46:753-5.

23. Delcour J, Ferain T, Deghorain M, Palumbo E, Hols P. The biosynthesis and functionality of the cell-wall of lactic acid bacteria. Antonie Van Leeuwenhoek. 1999:76:159-84.

24. Zonenschain D, Rebecchi A, Morelli L. Erythromycin- and tetracyclineresistant Lactobacilli in Italian fermented dry sausages. J Appl Microbiol. 2009;107:1559-68.

25. Ocana V, Silva C, Nader-Macias ME. Antibiotic susceptibility of potentially probiotic vaginal Lactobacilli. Infect Dis Obstet Gynecol. 2006;2006:18182.

26. Wong A, Gehring C. Computational identification of candidate nucleotide cyclases in higher plants. Methods Mol Biol. 2013;1016:195-205.

27. Rosander A, Connolly E, Roos S. Removal of antibiotic resistance gene-carrying plasmids from Lactobacillus reuteri ATCC 55730 and characterization of the resulting daughter strain, L. reuteri DSM 17938. Appl Environ Microbiol. 2008;74:6032-40

\section{Submit your next manuscript to BioMed Central and take full advantage of:}

- Convenient online submission

- Thorough peer review

- No space constraints or color figure charges

- Immediate publication on acceptance

- Inclusion in PubMed, CAS, Scopus and Google Scholar

- Research which is freely available for redistribution 